\title{
COMPARISON OF ARGON PLASMA COAGULATION AND FORMALIN INSTILLATION IN THE TREATMENT OF RADIATION-INDUCED HAEMORRHAGIC PROCTOCOLITIS
}

\author{
Muhammad Adnan Masood, Hala Mansoor, Muhammad Qayyum Khan \\ Department of Internal Medicine, Shaukat Khanum Memorial Cancer Hospital and Research Centre, Lahore, \\ Pakistan
}

Received: 30 October 2014 / Accepted: 17 April 2015

\begin{abstract}
Background: Radiotherapy is routinely used in the treatment of pelvic malignancies and about $2-5 \%$ of these patients develop radiation-induced proctitis or proctocolitis. This complication of radiotherapy is treated in different ways. Two of these treatments, argon plasma coagulation (APC) and formalin instillation, have both been reported as to be successful modalities, but data comparing them are scarce. We conducted this study to compare these two treatment options.
\end{abstract}

Methods: We reviewed the charts of patients who had radiation-induced proctocolitis and who were treated endoscopically at our tertiary care cancer centre with either APC or formalin instillation. Outcomes of the two treatments were compared in terms of bleeding control after the first session of treatment, the number of sessions required and the final response to therapy.

Results: Out of a total of 26 patients presenting with haemorrhagic radiation proctocolitis, 11 were treated with APC and 15 with formalin instillation. Success after the first session was $53 \%$ in the formalin instillation group compared to $18 \%$ in the APC-treated group. On repeated sessions, the final response to both treatment modalities was comparable.

Conclusion: Efficacy of APC and formalin instillation in the treatment of haemorrhagic radiation proctocolitis is comparable although formalin showed a better outcome after the first session.

Key words: Argon plasma coagulation, formalin instillation, proctitis, radiation-induced colitis

\section{Introduction}

Radiation-induced proctitis or proctocolitis is a complication of radiotherapy used to treat pelvic malignancies, especially prostate cancer, in which its occurrence is reported to be as high as $80 \% .^{[1]}$ The presentation of radiation-induced proctocolitis varies. Symptoms include urgency, diarrhoea, tenesmus, rectal pain and bleeding per rectum.

On endoscopy, multiple telangiectatic vessels are found which bleed to touch. Histopathology in the initial phase shows damaged vascular endothelium, but later, mucosal ulcers and neovascularisation are found. In cases of

Correspondence: Dr. Muhammad Adnan Masood, Department of Internal Medicine, Shaukat Khanum Memorial Cancer Hospital and Research Centre, Johar Town, Lahore, Pakistan.

Email: madnan@skm.org.pk severe disease, extensive fibrosis, fistulas and strictures can be seen. Rupture of telangiectatic vessels and oozing from friable ischaemic mucosa leads to haemorrhagic manifestations of the disease. A range of options is available for the treatment of this condition including hyperbaric oxygen, sucralfate enemata, 5-aminosalicylic acid and steroid enemata as medical therapies while among endoscopic options, argon plasma coagulation (APC), formalin instillation and Nd: YAG laser are currently available. ${ }^{[2-5]}$ Surgical treatment options include defunctioning colostomy and resection of affected colon. All of these options have both advantages and disadvantages.

In APC, ignition of argon gas is used to coagulate the telangiectatic vessels. A success rate of $81 \%$ has been reported with APC in haemorrhagic radiation proctitis. ${ }^{[6]}$ Formalin instillation was described in the late 1960 s 
for the treatment of haemorrhagic cystitis. It works by sclerosing the telangiectatic vessels and thus controls bleeding. The same mechanism is used in the treatment of radiation-induced proctocolitis. ${ }^{[7]}$ There are scarce data available regarding the comparison of these endoscopic modalities of treatment for haemorrhagic proctocolitis. The aim of this study was to compare these two treatment options in terms of outcomes.

\section{Methods}

\section{Setting}

This study was carried out at Shaukat Khanum Memorial Cancer Hospital and Research Centre (SKMCH and RC), a 189-bed cancer tertiary care cancer centre in Lahore, Pakistan. This study was approved by the Institutional Review Board of SKMCH and RC. We reviewed the charts of all patients who underwent endoscopic treatment for bleeding per rectum and were diagnosed as having radiation-induced injury at our institution between 2008 and 2013. All endoscopies were performed by one of two experienced endoscopists. All procedures were carried out under conscious sedation, using midazolam. One group of patients was treated with APC. We used the VIO $200 \mathrm{~S}$ ERBE argon plasma coagulator (Germany), with an endfiring probe, $2.7-3.2 \mathrm{~mm}$ in size. Argon gas flow was $2 \mathrm{~L} / \mathrm{min}$ and the electrical power settings were $20-30 \mathrm{~W}$. All the telangiectatic vessels were treated in a single session and painting of the entire mucosa was avoided as far as possible. All the visible lesions on the forward view were treated first and then the procedure was repeated in retroflexion. The other group was treated with formalin instillation. $60 \mathrm{ml}$ of $5 \%$ formalin was used in each patient, $20 \mathrm{ml}$ in each position i.e., left lateral, supine and right lateral. Contact time was $2 \mathrm{~min}$ in each position. Patients were managed on an outpatient basis and were asked to follow-up in case of persistence of bleeding. Followup was completed by a review of medical records. We collected demographic data of all the patients who were diagnosed with radiation-induced proctitis, proctocolitis or colitis at endoscopy and the severity of their disease was graded by review of photographs and videos of the lesions. We categorised lesions into Grade 1 if there was a single lesion, Grade 2 if there were multiple but non-confluent lesions and Grade 3 if there were multiple confluent lesions. We compared the APC and formalin groups for a response after the first session, calculated the total number of sessions, whether alternative treatments were used and the final outcome in terms of success or failure of endoscopic treatment in controlling bleeding post-therapy.

\section{Results}

We saw a total of 26 patients with haemorrhagic proctocolitis. The mean age of patients in this cohort was $57 \pm 11$ years. $17(65.4 \%)$ patients were females. Radiotherapy was used in the treatment of cervical cancer in $12(46 \%)$, of prostate cancer in $6(23 \%)$, of endometrial cancer in $4(15 \%)$, carcinoma of the anal canal in $2(8 \%)$ and bladder carcinoma in $2(8 \%)$. The mean duration from the end of radiotherapy to the presentation with haemorrhagic proctocolitis was 11 months (range 4-21 months). On endoscopy, 14 (53.8\%) had inflammation limited to the rectum (proctitis), 7 (27\%) had colitis and 5 (19.2\%) had proctocolitis. 11 patients were treated with APC and 15 with formalin instillation as the first modality. $82 \%$ $(9 / 11)$ patients in the APC group and $80 \%(12 / 15)$ in the formalin group had Grade 3 disease. Successful cessation of haemorrhagic manifestations without any recurrence was seen in 8/15 (53\%) patients in the formalin instillation group and in 2/11 (18\%) patients in the APC group. None of the patients in the formalin instillation group required more than 2 sessions of treatment. The median number of sessions in the APC group was 2 (range: 1-4) while in the formalin instillation group the median number of sessions was 1 (range: 1-2). Alternate or additional therapy was used in eight patients, four from each group. Alternate therapy included formalin instillation in three and steroid enemata in one patient in the APC group. Formalin therapy was instituted after a single unsuccessful session of APC in 2 patients and after three sessions in 1 patient. None of the patients received an alternate therapy before or during the first session of APC. Alternate therapies in the formalin instillation group were oral mesalazine in two patients, steroid enema in one and sucralfate enema in one patient. None of the patients in the formalin group had APC, despite the failure of the primary modality. Finally, 18 patients had successful medical therapy to control the haemorrhagic manifestations of radiation-induced proctocolitis, while one required surgical treatment. Others resolved spontaneously, later, but not within 2 weeks of therapy. 
Table of comparison between two groups

\begin{tabular}{|c|c|c|c|}
\hline Patients & APC group & Formalin instillation group & $P$-value \\
\hline Number of patients & 11 & 15 & \\
\hline Mean age & 61 & 54.2 & \\
\hline Gender & & & 0.87 \\
\hline Males & $4(36.4 \%)$ & $5(33.3 \%)$ & \\
\hline Females & $7(63.6 \%)$ & $10(66.7 \%)$ & \\
\hline Diagnosis & & & 0.40 \\
\hline Proctitis & 7 & 7 & \\
\hline Proctocolitis & 1 & 4 & \\
\hline Colitis & 3 & 4 & \\
\hline \multicolumn{4}{|l|}{ Severity } \\
\hline Grade 3 & $9(82 \%)$ & $12(80 \%)$ & \\
\hline Grade 2 & $2(18 \%)$ & $2(13 \%)$ & 0.65 \\
\hline Grade 1 & 00 & $1(7 \%)$ & \\
\hline Mean no of sessions & 1.81 & 1.4 & \\
\hline Median no of sessions & 2 & 1 & 0.06 \\
\hline Responders after first session & $2(18 \%)$ & $8(53 \%)$ & \\
\hline Number of patients requiring alternate therapy & 4 & 4 & 0.33 \\
\hline Final responders & $9(81 \%)$ & $10(67 \%)$ & \\
\hline
\end{tabular}

\section{Discussion}

Radiation-induced injuries are not uncommon in pelvic malignancies treated with radiotherapy. Successful management of bleeding, as well as other symptoms of radiation-induced proctocolitis, is challenging. There are multiple options available, but the superiority of one over the other is not yet established and it is usually the endoscopist's preference as to which modality to employ. Most studies of the various treatment options have reported partial success. These options include sucralfate enemata, steroid enemata, sulfasalazine, 5-ASA, either orally or as an enema, APC, formalin instillation and Nd: Yag laser ${ }^{[8]}$ Recently, hyperbaric oxygen therapy has been shown to have promising results but its cost and limited availability limits its use ${ }^{[9]}$ All of these treatment options have their advantages and disadvantages.

APC is cost-effective, widely-available, relatively easy to learn and apply and has a low risk of complications. Its mechanism involves the application of bipolar diathermy current which is conducted by argon gas through the APC catheter. It has a limited and predictable depth of coagulation which makes it safe. ${ }^{[10]}$ However, it often requires multiple sessions to control bleeding and is associated with a risk of stricture formation and persistent ulceration. ${ }^{[11,12]}$ Previous studies have shown response rates of $80-90 \%$ in haemorrhagic proctocolitis when treated with repeated sessions of APC. None of these studies assessed the first session response, however. One of the reasons for the low overall success rate in our study as compared to previous studies is a lower number of treatment sessions. Our median number of sessions was two while in previous studies, up to eight sessions of therapy have been reported. ${ }^{[11,12]}$ Complication rates with APC have been quite variable in previous studies. One study reports post-procedure pain in $20 \%$, and severe complications such as excessive bleeding, necrosis and perforation in $3 \%$ of patients. ${ }^{[13]}$ No symptomatic complications were seen in our cohort, but we cannot rule out the possibility of asymptomatic complications as follow-up colonoscopies were not performed routinely. A possible reason for the absence of overt complications in our study could be the low power settings (20-30 W compared to $50-60 \mathrm{~W}$ reported in other studies) used for AOC at our institution. This has previously been associated with a low incidence of complications. ${ }^{[13]}$ The same factor could be responsible for the lower success rate of our procedures. We could not find any data that compared the success rate of APC at 
different power settings. Similarly, there are very few data on the comparison of APC with formalin instillation and the role of adjuvant medical measures, such as pharmacologic agents given as enemata in radiation-induced proctocolitis. In previous studies, APC was used mainly after the failure of medical measures, but we used it before any other measure followed by alternative therapies in failed cases. The use of formalin instillation is derived from its use in haemorrhagic cystitis. There were initial reports of the use of formalin soaked gauze for haemorrhagic proctocolitis, which later led to its use by endoscopic instillation. The success rate of formalin instillation has been reported to be as high as $60 \%$ in previous studies. ${ }^{[14]}$ We also reported a success rate of $53 \%$ after the first session of the procedure, which is similar to previous studies.

There is no prospective trial available in literature comparing the APC with other endoscopic treatment modalities in haemorrhagic proctocolitis. There is only one study which compares APC with formalin instillation and this shows APC to be much more effective (78.5\%) than formalin instillation $(27.2 \%)$ in control of bleeding. ${ }^{[15]}$ However, our study differs in APC settings and formalin dosage and in the fact that symptomatic relief has been used as a primary measure of outcome. A previous study had used a 10\% rise in haemoglobin as a primary outcome measure, which might well be achieved with only partial control of bleeding.

\section{Conclusion}

APC and formalin instillation are effective options to control the haemorrhagic manifestations of radiationinduced proctocolitis. Formalin instillation appears more effective in terms of first session response, but after multiple sessions, the success rates with both treatment modalities are comparable.

\section{Conflict of Interest}

The authors declare that they have no conflict of interest.

\section{References}

1. Moore EM, Magrino TJ, Johnstone PA. Rectal bleeding after radiation therapy for prostate cancer: Endoscopic evaluation. Radiology 2000;217:215-8.

2. Melko GP, Turco TF, Phelan TF, et al. Treatment of radiation-induced proctitis with sucralfate enemas. Ann Pharmacother 1999;33:1274-6.

3. Chun M, Kang S, Kil HJ, et al. Rectal bleeding and its management after irradiation for uterine cervical cancer. Int J Radiat Oncol Biol Phys 2004;58:98-105.

4. Gul YA, Prasannan S, Jabar FM, et al. Pharmacotherapy for chronic hemorrhagic radiation proctitis. World J Surg 2002;26: 1499-502.

5. Ventrucci M, Di Simone MP, Giulietti P, et al. Efficacy and safety of Nd: YAG laser for the treatment of bleeding from radiation proctocolitis. Dig Liver Dis 2001;33:230-3.

6. Sebastian S, O'Connor H, O'Morain C, et al. Argon plasma coagulation as first-line treatment for chronic radiation proctopathy. J Gastroenterol Hepatol 2004;19:1169-73.

7. Rubinstein $\mathrm{E}$, Ibsen $\mathrm{T}$, Rasmussen RB, et al. Formalin treatment of radiation-induced hemorrhagic proctitis. Am J Gastroenterol 1986;81:44-5.

8. Baum CA, Biddle WL, Miner PB Jr. Failure of 5-aminosalicylic acid enemas to improve chronic radiation proctitis. Dig Dis Sci 1989;34:758-60.

9. Woo TC, Joseph D, Oxer H. Hyperbaric oxygen treatment for radiation proctitis. Int J Radiat Oncol Biol Phys 1997;38: 619-22.

10. Farin G, Grund KE. Technology of argon plasma coagulation with particular regard to endoscopic applications. Endosc Surg Allied Technol 1994;2:71-7.

11. Tjandra JJ, Sengupta S. Argon plasma coagulation is an effective treatment for refractory hemorrhagic radiation proctitis. Dis Colon Rectum 2001;44:1759-65.

12. Tagkalidis PP, Tjandra JJ. Chronic radiation proctitis. ANZ J Surg 2001;71:230-7.

13. Canard JM, Védrenne B, Bors G, et al. Long term results of treatment of hemorrhagic radiation proctitis by argon plasma coagulation. Gastroenterol Clin Biol 2003;27:455-9.

14. Mathai V, Seow-Choen F. Endoluminal formalin therapy for haemorrhagic radiation proctitis. Br J Surg 1995;82:190.

15. Alfadhli AA, Alazmi WM, Ponich T, et al. Efficacy of argon plasma coagulation compared to topical formalin application for chronic radiation proctopathy. Can J Gastroenterol 2008;22:129-32. 